\title{
Comparison of ultrasonography and X-ray test for lateral malleolar fracture in ankle sprain
}

\author{
Hamideh FeizDisfani ${ }^{\oplus}$ Ehsan Bolvardi ${ }^{\oplus}$, Mohadeseh Shourabi ${ }^{\circledR}$, Mohammad davood Sharifi ${ }^{\oplus}$, \\ Seyed Mohammad Mousavi ${ }^{\circledR}$, Roohie Farzaneh ${ }^{*}$
}

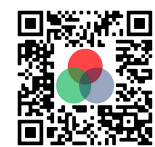

Use your smartphone to scan this QR code and download this article

Department of Emergency Medicine, Faculty of Medicine, Mashhad

University of Medical Sciences, Iran

Correspondence

Roohie Farzaneh, Department of Emergency Medicine, Faculty of Medicine, Mashhad University of Medical Sciences, Iran

Email: Faezanehrh@.mums.ac.ir

History

- Received: Jun 18, 2020

- Accepted: Aug 04, 2020

- Published: Aug 31, 2020

DOI : 10.15419/bmrat.v7i8.624

\section{Check for updates}

\section{Copyright}

(c) Biomedpress. This is an openaccess article distributed under the terms of the Creative Commons Attribution 4.0 International license.

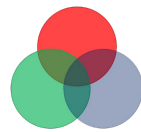

\begin{abstract}
Introduction: The use of ultrasonography for diagnosing musculoskeletal injuries, especially fractures, in the emergency department is on the rise because of its good diagnostic value. This study aimed to evaluate the diagnostic value of bedside ultrasonography in detecting the patients suffering from lateral malleolar fractures with an ankle sprain mechanism. Methods: This prospective study was conducted on patients having acute ankle injuries with ankle sprain mechanism and diagnosed with lateral malleolar tenderness. All patients underwent bedside ultrasonography with a $7.5-10 \mathrm{MHz}$ probe by an emergency medicine specialist who was assisted by a radiologist. Next, they underwent lateral ankle and anteroposterior (AP) X-rays by another emergency medicine specialist who was blinded from the ultrasonography results. The ultrasonography and X-Ray results were then compared. Results: A total of 244 patients participated in this study, of whom 92 (37.70\%) were diagnosed with lateral malleolar fracture through bedside ultrasonography and $X$-Ray tests. The results showed that ultrasonography had a sensitivity of $96.84 \%$ and a specificity of $97.31 \%$. The positive likelihood ratio (PLR) and negative likelihood ratio (NLR) were 36.07 and 0.0325 , respectively, and the positive and negative predictive values of bedside ultrasonography were $95.83 \%$ and $97.98 \%$, respectively. Finally, the results indicated a percent agreement (accuracy) of $97.13 \%$ between the two tests with Kappa coefficient of 0.94 ( $z=14.68$, $P$ value $<0.01$ ). Conclusion: The results of this study showed that bedside ultrasonography has a high sensitivity and specificity in the diagnosis of lateral malleolar fractures with an ankle sprain mechanism. Conducting further studies will lead to the use of this diagnostic test in the emergency department.

Key words: Ultrasonography, Lateral Malleolar Fractures, Emergency Department
\end{abstract}

\section{INTRODUCTION}

Ankle injuries are among the most common traumatic injuries in patients admitted to the emergency department, accounting for over 5 million emergency department visits annually ${ }^{1,2}$. As one of the most common injuries, ankle sprain has a prevalence of 52.7 to 60.9 per 10,000 people, as reported by recent studies $^{3}$, and can cause impairment in the patients' quality of life and decrease their performance due to its high prevalence and severity ${ }^{4,5}$. It can even cause long-term disabilities in $60 \%$ of the people affected ${ }^{6,7}$. Ankle sprain refers to a series of ligamentous and nonligamentous injuries to the ankle, most often caused by severe ankle twist inward, with the highest incidence among athletes and those having motorcycle accidents $^{3,8}$. Avulsion fractures at tendon junctions may occur if ligament injuries are severe. The fractures can occur in lateral and medial malleoli, lateral process of talus, lateral calcaneus, posterior malleolus, or fifth metatarsal base ${ }^{3}$. A combination of clinical and radiological examinations is commonly used for initial diagnosis of the fractures with an ankle sprain mechanism, amongst which X-ray is the simplest and most common radiological diagnostic procedure requested for these patients by an emergency medicine specialist ${ }^{9,10}$

On the other hand, it has been shown that the results of radiography for fractures with an ankle sprain mechanism are negative in $70-80 \%$ of cases ${ }^{11-14}$. The use of bedside ultrasonography has increased in recent decades due to its acceptability in the diagnosis of different fractures and is now widely used by physicians ${ }^{15,16}$. The results of various studies have shown that bedside ultrasonography can be a reliable and helpful diagnostic tool for fractures with an ankle sprain mechanism due to its advantages such as ease of use, cheapness, mobility, bedside use, lack of radiation exposure for patients, and patient satisfaction $^{11,12,16-18}$. In this regard, studies have indicated that bedside ultrasonography can diagnose a variety of fractures, such as the ones in the fifth metatarsal and metacarpal bones ${ }^{16,18}$, ankle ${ }^{17}$, and 
occult scaphoid ${ }^{15}$, with high sensitivity and specificity.

Given the limited number of evidence and results on the diagnostic value of bedside ultrasonography in the diagnosis of malleolar fractures with ankle sprain, this study was carried out to evaluate the diagnostic value of bedside ultrasonography in the diagnosis of lateral malleolar fractures with an ankle sprain mechanism in the emergency department.

\section{MATERIALS — METHODS}

This prospective blinded study was carried out on patients admitted to the emergency department of Shahid Hasheminejad Hospital in Mashhad, Iran in 2017. Having received permission from the Ethics Committee of Mashhad University of Medical Sciences, the researchers selected the subjects with acute ankle injuries with an ankle sprain mechanism who were over 18 years of age and had lateral malleolar tenderness with normal neurovascular limbs. The patients were entered into the study, prior to which their informed consent was obtained. The exclusion criteria were as follows: open wound and bleeding at the site of injury, impossibility of performing two diagnostic tests (bedsides ultrasonography and X-ray) on the subjects, previous history of fracture at the site of injury, unwillingness to participate in the study, and being unblinded from the diagnostic test results by the radiologist. All bedside ultrasonography scans were done with a 7.5-10 $\mathrm{MHz}$ probe by an emergency medicine specialist who was assisted by a single radiologist, and fracture diagnoses were made based on cortex disruption. Lateral ankle and anteroposterior (AP) X-rays were then performed on each subject by another emergency medicine specialist and radiologist who were unaware of the ultrasound results. The results of the ultrasonography and X-ray tests were collected and compared using a study checklist.

In this study, sensitivity was calculated by dividing true positives by the total number of positives (including true and false ones). On the other hand, specificity was calculated by dividing true negatives by the total number of negatives (true and false ones). Positive and negative likelihood ratios were also calculated by dividing the test sensitivity by 1 -specificity (Equation (1)) and dividing 1-sensitivity by the test specificity (Equation (2)), respectively.

\section{Equation 1:}

$$
P L R=\frac{\text { Sensitivity }}{1-\text { Specificity }}
$$

Equation 2:

$$
P L R=\frac{\text { Sensitivity }}{1-\text { Specificity }}
$$

\section{STATISTICAL ANALYSIS}

Descriptive statistics such as mean, standard deviation, frequency and frequency percentage were used for data description. Sensitivity, specificity, positive predictive value (PPV), negative predictive value (NPV), Positive Likelihood ratio (+LR), Negative Likelihood ratio (-LR), and kappa statistic were also used to evaluate the diagnostic value of bedside ultrasonography, compared to that of X-ray. The accuracy of ultrasonography was calculated by dividing the sum of total true positives and true negatives obtained from the two tests by the total number of subjects. Furthermore, the area under the ROC curve was used to evaluate the diagnostic value of bedside ultrasonography for diagnosing lateral malleolar fractures. The statistical analysis was performed using Stata12 software (StataCorp LLC, College Station, TX, USA), and the significance level was considered as $\mathrm{p}<0.05$.

\section{RESULTS}

A total of 244 individuals with the mean age of $35.81 \pm 10.61$ years participated in this study, of whom 96 (39.34\%) showed positive results and 148 (60.66\%) showed negative results of fracture diagnosis through bedside ultrasonography. In addition, 95 patients (38.93\%) had positive results while 149 patients (61.07\%) had negative results for fracture diagnosis by X-Ray. Overall, 92 patients (37.70\%) were diagnosed with lateral malleolar fracture by both bedside ultrasonography and X-Ray tests, and 145 (59.43\%) were diagnosed with no fracture.

Evaluation of diagnostic value of ultrasonography in the diagnosis of lateral malleolar fractures showed that the sensitivity and specificity of bedside ultrasonography were $96.84 \%$ and $97.31 \%$, respectively. Furthermore, positive and negative likelihood ratios were 36.07 and 0.0325 , respectively. Moreover, the positive predictive value of bedside ultrasonography in the diagnosis of lateral malleolar fractures was $95.83 \%$ and its negative value was $97.98 \%$. Finally, the results showed that the percent agreement (accuracy) between the two tests was 97.13\%. Examining the kappa coefficient between the two tests also showed that both bedside ultrasonography and X-ray tests had a kappa coefficient of 0.94 which was statistically significant $(\mathrm{z}=14.68, \mathrm{p}<0.01)$ Table 1 . The area under the ROC curve for bedside ultrasonography was 0.97 as well (95\% Confidence Interval: 0.948 $-0.99)$.

The present study aimed to investigate the diagnostic value of bedside ultrasonography in the diagnosis of lateral malleolar fractures with an ankle sprain 
Table 1: Diagnostic value of ultrasonography in diagnosis of lateral malleolar fractures with ankle sprain

\begin{tabular}{|c|c|c|c|c|c|c|c|}
\hline \multicolumn{2}{|l|}{ Test } & \multicolumn{2}{|c|}{ X-Ray } & \multirow[t]{3}{*}{ Sensitivity } & \multirow[t]{3}{*}{ Specificity } & \multirow[t]{3}{*}{$\begin{array}{c}\text { Positive } \\
\text { Likelihood Ratio }\end{array}$} & \multirow[t]{3}{*}{$\begin{array}{c}\text { Negative } \\
\text { Likelihood Ratio }\end{array}$} \\
\hline \multirow{4}{*}{$\begin{array}{l}\text { Bedside } \\
\text { Ultrasonography }\end{array}$} & & With & Without & & & & \\
\hline & & Fracture & Fracture & & & & \\
\hline & Positive & 92 & 4 & \multirow{3}{*}{$96.84 \%$} & \multirow{3}{*}{$97.31 \%$} & \multirow{3}{*}{36.07} & \multirow{3}{*}{0.0325} \\
\hline & Negative & 3 & 145 & & & & \\
\hline Total & & 95 & 149 & & & & \\
\hline \multicolumn{2}{|c|}{$\begin{array}{l}\text { Percent Agreement } \\
\text { (Accuracy) }\end{array}$} & \multicolumn{2}{|c|}{$97.13 \%$} & & & & \\
\hline Kappa Statistic & & \multicolumn{2}{|c|}{0.94} & & & & \\
\hline
\end{tabular}

mechanism. The results showed that bedside ultrasonography had a good acceptability in the diagnosis of such fractures such that over $96 \%$ of the patients with lateral malleolar fractures (sensitivity of 96.84\%) were identified in this study. Also, bedside ultrasonography had a specificity of $97.31 \%$ in the diagnosis of such fractures in the present study, indicating the high capability of this diagnostic tool in the diagnosis of musculoskeletal fractures. The diagnostic value of bedside ultrasonography in the diagnosis of different fractures has been evaluated in recent decades and it has been well-demonstrated that bedside ultrasonography has good sensitivity and specificity in fracture diagnosis ${ }^{19,20}$

However, there is little evidence on the role of ultrasonography in the diagnosis of lateral malleolar fractures. In their study, Shojaee et al. ${ }^{17}$ stated that ultrasonography had a high diagnostic value in the diagnosis of ankle fractures such that its sensitivity and specificity were $98.9 \%$ and $86.4 \%$, respectively. The PLR in their study was 16 , which is consistent with the results of our study and demonstrates the capability of ultrasonography to increase the pre-test probability of lateral malleolar fractures. Yesilaras et al. ${ }^{16}$ showed that bedside ultrasound had sensitivity and specificity of $97.7 \%$ and $100 \%$, respectively, in the diagnosis of fifth metatarsal fractures, which is consistent with the results of the present study. In a study by Atilla et al. ${ }^{10}$, it was found that bedside ultrasound had $87.3 \%$ sensitivity and $96.4 \%$ specificity for diagnosing ankle fractures. In this study, significant differences were found between sensitivity and specificity of ultrasonography with respect to the fracture site such that the sensitivity was about $86 \%, 71 \%, 100 \%$, and $93 \%$ in lateral malleolus, medial malleolus, fifth metatarsal and navicular tenderness fractures, respectively. Trinh et al. ${ }^{21}$ also reported the sensitivity and specificity as $100 \%$ and $89.9 \%$, respectively, for ultrasonography in the diagnosis of lateral malleolar fractures compared to radiography, which is consistent with our results. In their research study, Ekinci et al. ${ }^{11}$ showed that most of the fractures caused by foot and ankle traumas were those of lateral malleolus and fifth metatarsal. Regarding the evaluation of ultrasonography in the diagnosis of lateral malleolus and fifth metatarsal fractures, their findings showed that the sensitivity and specificity of ultrasonography were $100 \%$ and $99.1 \%$, respectively, which was somehow consistent with our study. Finally, according to various studies, ultrasonography is an operator-based imaging technique and the heterogeneity among those interpreting the results is of great importance. Therefore, the interrater reliability in this study was calculated using the kappa coefficient of about 0.94 , indicating significant homogeneity between the two physicians (X-ray interpreter and ultrasound operator) who were blinded from the results.

Generalizability of the results is one of the limitations of this study since only the patients with acute ankle injury with ankle sprain mechanism were included. Hence, the ultrasound results are only generalizable to these patients and cannot be extended to the general population. The use of other diagnostic methods, such as computed tomography and MRI, can be helpful in investigating the diagnostic value of ultrasonography, but they were not used in this study due to their high costs.

\section{CONCLUSION}

The results of this study showed that bedside ultrasonography had high sensitivity and specificity in the diagnosis of lateral malleolar fractures with an ankle sprain mechanism, and could be used in the emergency department due to its advantages compared to $\mathrm{X}$-Ray. However, more studies are needed to confirm its diagnostic acceptability. 


\section{ABBREVIATIONS}

AP: Anteroposterior

NLR: Negative likelihood ratio

NPV: Negative predictive value

PLR: Positive likelihood ratio

PPV: Positive predictive value

\section{ACKNOWLEDGMENTS}

The authors of this study are grateful to all the personnel of Imam Reza Hospital as well as the ViceChancellor for Research, Mashhad University of Medical Sciences, for their contribution to the implementation of this research projects.

\section{AUTHOR'S CONTRIBUTIONS}

H Feiz Disfani conceptualized and designed the study, MD Sharif contributed in data collection and managing analysis, E Bolvardi and M Shourabi collected the Data, S M Mousavi and R Farzaneh Contributed in writing and approving the study. All authors read and approved the final manuscript.

\section{FUNDING}

This study was funded by Mashhad University of Medical Sciences.

\section{AVAILABILITY OF DATA AND MATERIALS}

Data and materials used and/or analyzed during the current study are available from the corresponding author on reasonable request.

\section{ETHICS APPROVAL AND CONSENT TO PARTICIPATE}

This study was conducted in accordance with the amended Declaration of Helsinki. The institutional review board (Ethics Committee of Mashhad University of Medical Sciences) approved the study, and all participants provided written informed consent.

\section{CONSENT FOR PUBLICATION}

Not applicable.

\section{COMPETING INTERESTS}

The authors declare that they have no competing interests.

\section{REFERENCES}

1. Ruth CJ. The surgical treatment of injuries of the fibular collateral ligaments of the ankle. JBJS. 1961;43(2):229-239. Available from: https://doi.org/10.2106/00004623-19614302000011.

2. Daniels CJ, Welk AB, Enix DE. Diagnostic ultrasonography of an ankle fracture undetectable by conventional radiography: a case report. Journal of chiropractic medicine. 2016;15(1):3541. PMID: 27069430. Available from: https://doi.org/10.1016/j. jcm.2016.02.005.

3. Rotheray KR, Cattermole GN. Rosen's emergency medicine: concepts and clinical practice. European Journal of Emergency Medicine. 2010;17(2):101-102. Available from: https: //doi.org/10.1097/MEJ.0b013e32833728f4.

4. Braun BL. Effects of ankle sprain in a general clinic population 6 to 18 months after medical evaluation. Archives of family medicine. 1999;8:143-148. PMID: 10101985. Available from: https://doi.org/10.1001/archfami.8.2.143.

5. Kerkhoffs GM, Rowe BH, Assendelft WJ, Kelly KD, Struijs PA, Van DC. Immobilisation and functional treatment for acute lateral ankle ligament injuries in adults. Cochrane Database of Systematic Reviews. 2002;(3):CD003762. Available from: https://doi.org/10.1002/14651858.CD002938.

6. Gerber JP, Williams GN, Scoville CR, Arciero RA, Taylor DC. Persistent disability associated with ankle sprains: a prospective examination of an athletic population. Foot \& ankle international. 1998;19(10):653-660. PMID: 9801078. Available from: https://doi.org/10.1177/107110079801901002.

7. Yeung M, Chan KM, So C, Yuan W. An epidemiological survey on ankle sprain. British journal of sports medicine. 1994;28(2):112-116. PMID: 7921910. Available from: https: //doi.org/10.1136/bjsm.28.2.112.

8. Haapamaki VV, Kiuru MJ, Koskinen SK. Ankle and foot injuries: analysis of MDCT findings. American Journal of Roentgenology. 2004;183(3):615-622. PMID: 15333345. Available from: https://doi.org/10.2214/ajr.183.3.1830615.

9. Marder RA. Current methods for the evaluation of ankle ligament injuries. JBJS. 1994;76(7):1103-1111. Available from: https://doi.org/10.2106/00004623-199407000-00022.

10. Atilla OD, Yesilaras M, Kilic TY, Tur FC, Reisoglu A, Sever M, et al. The accuracy of bedside ultrasonography as a diagnostic tool for fractures in the ankle and foot. Academic Emergency Medicine. 2014;21(9):1058-1061. PMID: 25269589. Available from: https://doi.org/10.1111/acem.12467.

11. Ekinci S, Polat O, Günalp M, Demirkan A, Koca A. The accuracy of ultrasound evaluation in foot and ankle trauma. The American journal of emergency medicine. 2013;31(11):15511555. PMID: 23992775. Available from: https://doi.org/10. 1016/j.ajem.2013.06.008.

12. Canagasabey MD, Callaghan MJ, Carley S. The sonographic Ottawa foot and ankle rules study (the SOFAR study). Emerg Med J. 2011;28(10):838-840. PMID: 20943841. Available from: https://doi.org/10.1136/emj.2009.088286.

13. Joshi N, Lira A, Mehta N, Paladino L, Sinert R. Diagnostic accuracy of history, physical examination, and bedside ultrasound for diagnosis of extremity fractures in the emergency department: a systematic review. Academic Emergency Medicine. 2013;20(1):1-15. PMID: 23570473. Available from: https: //doi.org/10.1111/acem.12058.

14. Dowdall H, Gee M, Brison RJ, Pickett W. Utilization of radiographs for the diagnosis of ankle fractures in Kingston, Ontario, Canada. Academic Emergency Medicine. 2011;18(5):555-558. PMID: 21545671. Available from: https://doi.org/10.1111/j.1553-2712.2011.01058.x.

15. Yıldırım A, Unlüer $E$, Vandenberk N, Karagöz A. The role of bedside ultrasonography for occult scaphoid fractures in the emergency department. Ulusal travma ve acil cerrahi dergisi Turkish journal of trauma \& emergency surgery: TJTES. 2013;19(3):241-245. PMID: 23720112. Available from: https: //doi.org/10.5505/tjtes.2013.64927.

16. Yesilaras M, Aksay E, Atilla OD, Sever M, Kalenderer O. The accuracy of bedside ultrasonography as a diagnostic tool for the fifth metatarsal fractures. The American journal of emergency medicine. 2014;32(2):171-174. PMID: 24342871. Available from: https://doi.org/10.1016/j.ajem.2013.11.009.

17. Shojaee $M$, Hakimzadeh F, Mohammadi $P$, Sabzghabaei $A$, Manouchehrifar M, Dolatabadi AA. Screening characteristics of ultrasonography in detection of ankle fractures. Emergency. 2016;4(4):188-191. PMID: 27800538. 
18. Aksay E, Yesilaras M, Kılıc TY, Tur FC, Sever M, Kaya A. Sensitivity and specificity of bedside ultrasonography in the diagnosis of fractures of the fifth metacarpal. Emerg Med J. 2015;32(3):221-225. PMID: 24154940. Available from: https: //doi.org/10.1136/emermed-2013-202971.

19. Rabiner JE, Khine H, Avner JR, Friedman LM, Tsung JW. Accuracy of point-of-care ultrasonography for diagnosis of elbow fractures in children. Annals of Emergency Medicine. 2013;61(1):9-17. PMID: 23142008. Available from: https: //doi.org/10.1016/j.annemergmed.2012.07.112.
20. Patil P, Dasgupta B. Role of diagnostic ultrasound in the assessment of musculoskeletal diseases. Therapeutic advances in musculoskeletal disease. 2012;4(5):341-355. PMID: 23024711. Available from: https://doi.org/10.1177/1759720X12442112.

21. Trinh E, McMillan D, Gough J, Brewer K. Emergency department use of ultrasonography to detect lateral ankle fractures. Annals of Emergency Medicine. 2004;44(4):S61-S62. Available from: https://doi.org/10.1016/j.annemergmed.2004. 07.203 . 